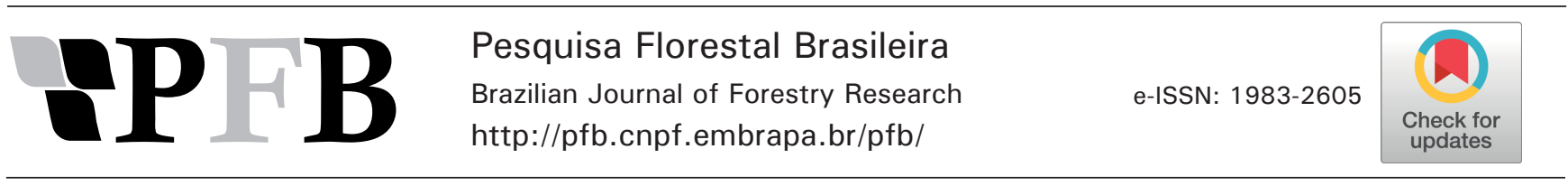

\title{
Variação radial e longitudinal da massa específica básica da madeira de Araucaria angustifolia com diferentes idades
}

\author{
Leonardo Antônio Moraes Zaque ${ }^{1}$ (i), Mayra Daniela Ferreira1(iD, Rafael Rodolfo Melo² (D) \\ 1Universidade Federal Rural do Mato Grosso, Campus de Sinop, Av. Alexandre Ferronato, Distrito Industrial, CEP 78557-267, Sinop, MT, Brasil \\ ${ }^{2}$ Universidade Federal Rural do Semi-Árido, Av. Francisco Mota, 572 - Bairro Costa e Silva, CEP 59625-900, Mossoró, RN, Brasil
}

"Autor correspondente:
rafael.melo@ufersa.edu.br

Termos para indexação:

Propriedades físicas

Medula

Densidade

Index terms:

Physical properties

Pith

Density

Histórico do artigo:

Recebido em 20/10/2016

Aprovado em 16/12/2017

Publicado em 05/07/2018

doi: 10.4336/2018.pfb.38e201601368

\begin{abstract}
Resumo - A massa específica da madeira é uma das propriedades mais importantes do ponto de vista prático, sendo utilizada como principal indicador para diversos tipos de uso. No entanto, mesmo se tratando de uma única espécie, esse parâmetro pode variar ao longo do fuste, seja no sentido base-topo e/ou medula-casca. Deste modo, a sua determinação torna-se essencial para qualificação da madeira de qualquer espécie florestal. O presente estudo teve como objetivo avaliar as variações radial e longitudinal da massa específica básica da madeira de Araucaria angustifolia (Bert.) O. Kuntze. para indivíduos de diferentes idades. Para isso, foram abatidas doze árvores com as idades de $23,25,28$ e 30 anos. Foram retirados discos a 10\%, 35\%, 55\% e 75\% da altura total de cada árvore e outro correspondente ao diâmetro a $1,30 \mathrm{~m}$ do solo. Para determinação da massa específica básica no sentido radial, foram retiradas três amostras de cada disco: próximo à medula, na região central e próximo à casca. Foi verificada redução da massa específica da base para o topo, no sentido longitudinal, e da medula-casca, no radial. Os indivíduos com mais idade apresentaram maiores valores de massa específica básica.
\end{abstract}

\section{Radial and longitudinal variation of Araucaria angustifolia wood basic density for different ages}

\begin{abstract}
The wood density is one of the most important property, and it is used as the main indicator for several types of use. However, this parameter can vary substantially along the stem, either in the bottom-top or pith-bark direction. Its determination becomes essential for the qualification of the wood of any forest species. This study aimed to evaluate the radial and axial variation the Araucaria angustifolia (Bert.) O. Kuntze wood density under different ages. Twelve trees with 23, 25, 28 and 30 years were felled. Discs were collected from $10 \%, 35 \%, 55 \%$ and $75 \%$ of tree height and another-from $1.3 \mathrm{~m}$ above ground level. From each disc three samples were taken from different positions in radial direction for density determination: near pith, central region and near bark. It was observed a reduction in density from bottom to top (longitudinal) and from pith-bark (radial). Older trees presented higher density values.
\end{abstract}

\section{Introdução}

A massa específica reflete a quantidade de matéria lenhosa por unidade de volume ou o volume de espaços vazios existentes em uma peça. Esse parâmetro é aceito como essencial para determinação da qualidade da madeira, quando se visa seu uso como matéria prima industrial ou energética, além da sua correlação com outras propriedades (Osborne, 2016).

A madeira do pinheiro-do-paraná (Araucaria angutifolia) apresenta massa específica básica média ponderada de $0,422 \mathrm{~g} \mathrm{~cm}^{-3}$, sendo considerada leve 
(Trevisan et al., 2016), o que a torna macia e pouco durável quando exposta ao tempo. O seu uso é indicado para forros, molduras, ripas, confecção de cabos de vassoura, caixotaria, brinquedos, carretéis e utensílios domésticos (Melo et al., 2010; Hilling et al., 2012; Curto et al., 2016).

As variações da massa específica dependem das espessuras das paredes celulares dos traqueídes. Valores mais altos desse parâmetro podem ser o resultado do aumento da espessura desses elementos ou de uma elevação na proporção em uma dada peça (Gatto et al., 2000; Delucis et al., 2013).

A determinação da massa específica e, principalmente, de sua variação dentro da árvore, tanto na direção radial (da medula para a casca), quanto no sentido longitudinal (da base para topo), aliada à variação na idade, são parâmetros essenciais para a caracterização da madeira, subsidiando sua indicação de uso para as mais diversas finalidades. Espécies que apresentam massa específica mais homogênea no interior do tronco possuem comportamento melhor nas operações de processamento, o que reflete em maior uniformidade nas outras propriedades tecnológicas (United States, 2010).

O lenho juvenil interfere consideravelmente na massa específica da madeira, principalmente quando se trata de espécies de rápido crescimento inicial. No entanto, alterações do espaçamento na implantação dos povoamentos florestais podem reduzir significativamente a intensidade dessa variação. Em plantios mais densos há uma maior competição entre os indivíduos, o que faz com que estes cresçam mais lentamente e, consequentemente, não apresentem grandes variações em suas dimensões celulares nessa fase inicial de crescimento. $\mathrm{Na}$ fase adulta ocorre, naturalmente, maior homogeneidade nas características dos componentes celulares, o que proporciona certa estabilidade na massa específica do lenho formado (Rolim \& Ferreira, 1974; Gatto et al., 2008; Peres et al., 2012).

A diferença de espessura nos anéis de crescimento também afeta a massa específica e qualidade da madeira de coníferas. Por esse motivo, a distância entre os anéis, pode ser utilizada como um parâmetro de fácil e rápida obtenção, para a estimativa das propriedades físicas e mecânicas da madeira (Melo et al., 2010).

Apesar de terem alguns resultados sobre a variação da densidade da madeira de araucaria (Melo et al., 2010; Hilling et al., 2012), ainda existem lacunas sobre as variações em diferentes idades de plantio. Portanto, este trabalho teve como objetivo avaliar a variação da massa específica básica no sentido radial e longitudinal da madeira de Araucaria angustiolia (Bert.) O. Kuntze de indivíduos com diferentes idades.

\section{Material e métodos}

Foram selecionadas árvores de Araucaria angustifolia em plantios homogêneos com 23, 25, 28 e 30 anos localizados na região leste do Estado de Santa Catarina.

Foram derrubadas três árvores por povoamento, sendo retirados discos com aproximadamente $5 \mathrm{~cm}$ de espessura aos $10 \%, 35 \%, 55 \%$ e $75 \%$ da sua altura total, além de um disco a 1,30 m do solo (DAP). Todo o material coletado foi identificado e encaminhado ao laboratório. De cada disco foram retirados três corpos de prova com as dimensões de $1,5 \mathrm{~cm}$ x 1,5 $\mathrm{cm}$ x $5,0 \mathrm{~cm}$, nas porções interna (próximo à medula), intermediária e externa (próximo à casca), conforme ilustrado na Figura 1.

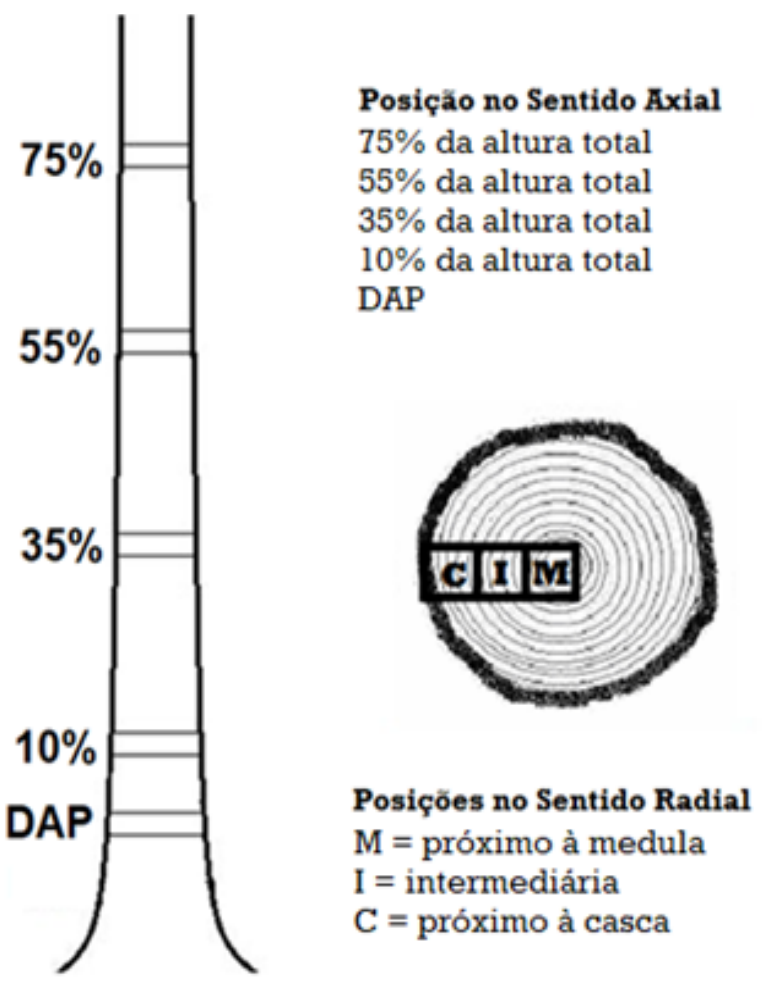

Figura 1. Posição das amostras ao longo do tronco. DAP = diâmetro a $1,30 \mathrm{~m}$ do solo.

\section{Determinação da massa específica básica}

Para determinação da massa específica básica foi adaptada a metodologia proposta por Vital (1984), 
onde os corpos de prova foram submersos em água até atingirem massa constante (completa saturação das paredes celulares). Em seguida, determinou-se o volume de cada amostra saturada e a massa seca da madeira (obtida após a secagem em estufa a $103^{\circ} \mathrm{C}$ ). A massa específica básica de cada corpo de prova foi calculada pela relação entre a massa seca e o volume saturado.

\section{Análise dos resultados}

Foi empregada análise com arranjo fatorial, em que foram avaliados três fatores: idade (23, 25, 28 e 30 anos); posição axial no tronco, com cinco níveis $(10 \%$, DAP, $35 \%, 55 \%$ e $75 \%$ ); e posição radial no tronco, com três níveis (próxima à medula, intermediária e próxima à casca). Na análise e avaliação dos ensaios foi empregado o teste de Scott-Knott a 5\% de significância para os fatores e interação detectados como significativos pelo teste de F. A análise de regressão foi empregada para estimar a massa específica básica média (aritmética) da madeira a partir da massa específica de amostras retiradas do DAP.

\section{Resultados e discussão}

A variação da massa específica básica para madeira de Araucaria angustifolia para os parâmetros de idade, posição axial e radial são apresentados na Tabela 1. Os valores de massa específica básica da madeira variaram entre $0,37 \mathrm{~g} \mathrm{~cm}^{-3}$ e $0,51 \mathrm{~g} \mathrm{~cm}^{-3}$.

A análise de variância apontou que a interação entre a idade e a variação longitudinal influenciou a massa específica básica da madeira de araucária. Resultados semelhantes foram observados por Hilling et al. (2012), que encontraram diferenças entre a massa específica básica ao longo do fuste nas diferentes idades na madeira de araucária.

Os indivíduos mais velhos de araucária apresentaram os maiores valores de massa específica básica. Rolim \& Ferreira (1974), em estudos realizados com $A$. angustifolia, observaram em madeira oriunda de plantios homogêneos com até 15 anos de idade que a massa específica aumentou da medula para a casca, no sentido radial, sendo esse crescimento acentuado até 9 anos e menos pronunciado a partir dessa idade. Os valores encontrados por esses autores foram de $0,37 \mathrm{~g} \mathrm{~cm}^{-3}$ a $0,52 \mathrm{~g} \mathrm{~cm}^{-3}$, sendo semelhantes aos deste trabalho. O aumento da massa específica básica do do lenho juvenil $\left(0,39 \mathrm{~g} \mathrm{~cm}^{-3}\right)$ para o lenho adulto
(048 $\left.\mathrm{g} \mathrm{cm}^{-3}\right)$, foi observado por Melo et al. (2010), onde evidenciaram a influência dos espaços entre os anéis de crescimento na massa específica da madeira.

Tabela 1. Variação de massa específica básica da madeira de Araucaria angustifolia para os parâmetros idade e posição no tronco.

\begin{tabular}{cccccc}
\hline \multicolumn{2}{c}{ Idade média } & \multicolumn{2}{c}{ Posição Axial } & \multicolumn{2}{c}{ Posição Radial } \\
\hline $\mathbf{( A n o s )}$ & $\mathbf{( \mathbf { g ~ c m } ^ { - 3 } )}$ & $\mathbf{( \% )}$ & $\left.\mathbf{( \mathbf { g ~ c m } ^ { - 3 }}\right)$ & - & $\mathbf{( \mathbf { g ~ c m } ^ { - 3 } )}$ \\
\hline 23 & $0,389 \mathrm{c}$ & DAP & $0,454 \mathrm{a}$ & Externa & $0,457 \mathrm{a}$ \\
25 & $0,404 \mathrm{~b}$ & 10 & $0,455 \mathrm{a}$ & Intermediária & $0,410 \mathrm{~b}$ \\
28 & $0,411 \mathrm{~b}$ & 35 & $0,414 \mathrm{~b}$ & Medula & $0,374 \mathrm{c}$ \\
30 & $0,451 \mathrm{a}$ & 55 & $0,381 \mathrm{c}$ & - & - \\
- & - & 75 & $0,365 \mathrm{c}$ & - & - \\
\hline
\end{tabular}

Médias seguidas pela mesma letra minúscula, em cada coluna, não diferem entre si pelo teste de Scott-Knott a 5\% de probabilidade.

Foi observada redução da massa específica básica no sentido radial, conforme o aumento da altura na árvore. Resultados semelhantes foram observados por Mattos et al. (2011), estudando araucária e duas espécies de Pinus. Para a variação radial, a massa específica da madeira aumentou no sentido da medula para casca. Segundo Amaral et al. (1971), em madeiras de araucárias a massa específica cresce da medula para casca, com uma tendência a se tornar constante mais próxima desta. Estes mesmos autores constataram diferenças entre massas específicas, ou seja, a região mais próxima da medula apresentou resultados distintos estatisticamente quando comparado com a região próxima a casca.

Na Figura 2 verifica-se que massa específica básica da madeira de araucária aumentou com a idade da árvore, comportamento similar ao verificado por Mattos et al. (2006). Estas variações podem ser decorrentes da maturidade do material analisado, das condições locais de crescimento e das características genéticas.

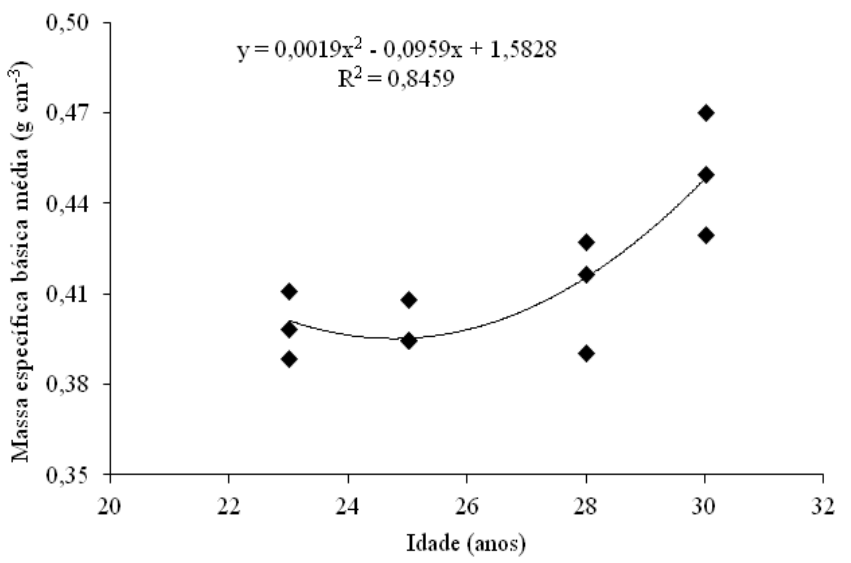

Figura 2. Correlação entre a massa específica básica média de Araucaria angustifolia e a idade. 
$\mathrm{Na}$ interação entre os fatores idade e variação longitudinal (Tabela 2) foi observado que a massa específica é maior quanto mais próxima da base, independente da idade da árvore. Para todas as posições ao longo do fuste, as árvores de maior idade foram as que apresentaram maior massa específica.

Tabela 2. Variação da massa específica básica de Araucaria angustifolia para interação entre os fatores idade e variação longitudinal.

\begin{tabular}{cccccc}
\hline \multirow{2}{*}{$\begin{array}{c}\text { Idade } \\
\text { (Anos) }\end{array}$} & \multicolumn{5}{c}{ Variação longitudinal } \\
\cline { 2 - 6 } & DAP & $\mathbf{1 0 \%}$ & $\mathbf{3 5 \%}$ & $\mathbf{5 5 \%}$ & $\mathbf{7 5 \%}$ \\
\hline 23 & $0,438 \mathrm{bA}$ & $0,420 \mathrm{bA}$ & $0,385 \mathrm{bB}$ & $0,361 \mathrm{bB}$ & $0,343 \mathrm{bB}$ \\
25 & $0,439 \mathrm{bB}$ & $0,489 \mathrm{aA}$ & $0,391 \mathrm{bC}$ & $0,360 \mathrm{bC}$ & $0,343 \mathrm{bC}$ \\
28 & $0,453 \mathrm{bA}$ & $0,446 \mathrm{bA}$ & $0,398 \mathrm{bB}$ & $0,392 \mathrm{aB}$ & $0,367 \mathrm{bB}$ \\
30 & $0,487 \mathrm{aA}$ & $0,466 \mathrm{aA}$ & $0,485 \mathrm{aA}$ & $0,411 \mathrm{aB}$ & $0,408 \mathrm{aB}$ \\
\hline
\end{tabular}

Médias seguidas pela mesma letra, minúscula na coluna e maiúscula na linha, não diferem entre si pelo teste de Scott-Knott a 5\% de probabilidade.

Para a análise da relação entre a massa específica básica média da madeira e a das amostras retiradas do DAP, verificou-se correlação linear entre os parâmetros, com um coeficiente de determinação de aproximadamente 0,78 (Figura 3 ).

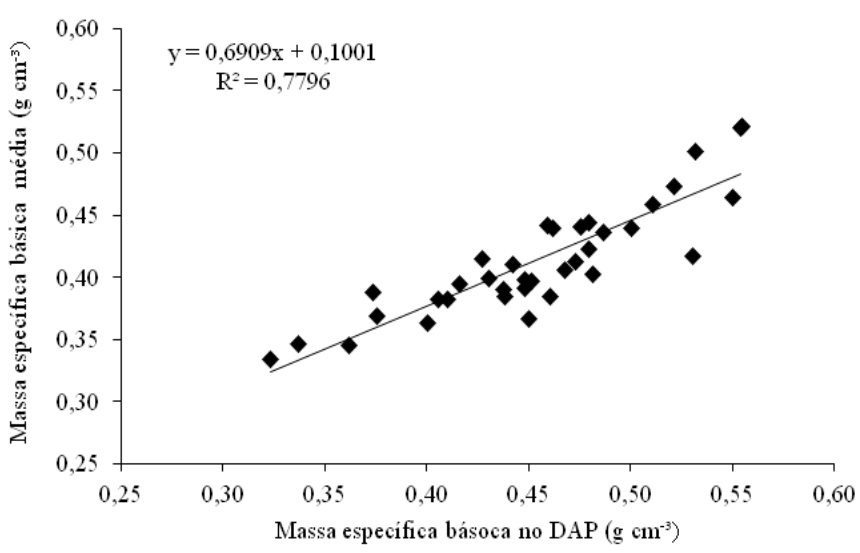

Figura 3. Correlação entre a massa específica básica média de Araucaria angustifolia e das amostras obtidas do DAP.

O incremento da massa específica no sentido radial é comumente verificado para diferentes espécies, com destaque para as de rápido crescimento (Mattos et al., 2011; Melo et al., 2013; Machado et al., 2014; Melo, 2015; Hein et al., 2016).

Em estudos realizados por Curto et al. (2016), em plantio de araucária, verificou-se que a massa específica apresentou aumento até por volta de $60 \%$ do fuste, tornando a diminuir na direção longitudinal, da base para o topo. Essa alteração foi ocasionada pela excessiva competição, provocando desuniformidade da madeira ao longo do fuste. Resultados semelhantes também foram observados por Trevisan et al. (2016), avaliando a variação axial da massa específica da madeira de araucária obtida de árvores com diferentes classes diamétricas.

$\mathrm{O}$ incremento de massa específica dos indivíduos com maior idade pode ser explicado pela presença das células adultas da araucária, as quais apresentam paredes celulares mais espessas. Conforme Santini et al. (2000), a presença de células proporcionalmente mais longas e de paredes mais espessas, assim como a maior proporção de lenho tardio, resultam em madeira com maior massa específica. Na análise realizada por Hilling et al. (2012), onde avaliou-se a interação entre idade e altura, não foram constatadas interações entre estes parâmetros, diferentemente da análise apresentada neste trabalho.

A massa específica básica obtida na altura do DAP foi um parâmetro seguro para estimar a massa específica média da madeira. A efetividade do uso da massa específica do DAP também foi verificada para as madeiras de Pinus elliottii (Melo et al., 2010) e Pinus taeda (Melo, 2015) para estimar a massa específica média da madeira.

\section{Conclusão}

A massa específica básica da madeira de Araucaria angustifolia foi maior na base e na posição mais externa das árvores.

As árvores com maior idade tiveram maiores valores de massa específica básica em relação às árvores de menores idades.

A massa específica básica determinada a partir de amostras obtidas a $1,30 \mathrm{~m}$ acima do solo pode ser empregada para estimar com precisão a massa específica média da árvore.

\section{Referências}

Amaral, A. C. B et al. Variação da densidade básica da madeira produzida pela Araucaria angustifolia (Bert.) O. Kuntze no sentido medula-casca em árvores do sexo masculino e feminino. Revista IPEF, n.2/3, p. 119-127, 1971.

Curto, R. A. et al. Wood density of Araucaria angustifolia from overstocked strand. Pesquisa Florestal Brasileira, v. 36, n. 85, p. 51-59, 2016. DOI: 10.4336/2016.pfb.36.85.963. 
Delucis, R. A. et al. Qualificação da madeira de três espécies de coníferas oriundas de reflorestamentos jovens. Scientia Forestalis, v. 41, n. 100, p. 477-484, 2013.

Gatto, D. A. et al. Análise comparativa das propriedades físicas e mecânicas da madeira de três coníferas de florestas plantadas. Ciência Florestal, v. 10, n. 1, p. 85-93, 2000. DOI: 10.5902/19805098397

Gatto, D. A. et al. Estimativa da idade de segregação do lenho juvenil a adulto por meio de parâmetros anatômicos para madeira de Luehea divaricata Mart. Ciência Florestal, v. 18, n. 4, p.535-540, 2008. DOI: $10.5902 / 19805098436$.

Hein, P. R. G. et al. Spatial variation of wood density, stiffness and microfibril angle along Eucalyptus trunks grown under contrasting growth conditions. Trees, v. 30, n. 3, p. 871-882, 2016. DOI: 10.1007/ s00468-015-1327-8.

Hilling, E. et al. Propriedades físicas da madeira de Araucauria angustifolia (Bert.) O. Kuntze em função da posição no fuste para diferentes idades. Cerne, v. 18, n. 2, 2012. DOI: 10.1590/S010477602012000200010 .

Machado, J. S. et al. Variation of wood density and mechanical properties of blackwood (Acacia melanoxylon $\mathrm{R}$. Br.). Materials and Design, v. 56, p. 975-980, 2014. DOI: 10.1016/j.matdes.2013.12.016.

Mattos, B. D. et al. Variação axial da densidade básica da madeira de três espécies de gimnospermas. Revista Brasileira de Ciências Agrárias, v. 6, n.1, p. 121-126, 2011. DOI: 10.5039/agraria. v6ila1080.

Mattos, P. P. et al. Caracterização física, química e anatômica da madeira de Araucaria angustifolia (Bert.) O. Kuntze. Colombo: Embrapa Florestas, 2006. 4 p. (Embrapa Florestas. Comunicado técnico, 160).
Melo, R. R. et al. Caracterização física e mecânica da madeira de Araucaria angustifolia (Bertol.) Kuntze. Agrária, v. 5, n. 1, p. 67-73, 2010. DOI:10.5039/agraria.v5ila515.

Melo, R. R. Radial and longitudinal variation of Pinus taeda L. wood basic density in different ages. Revista de Ciências Agrárias, v. 58, n. 2, p. 192-197, 2015. DOI: 10.4322/rca.1839.

Melo, R. R. et al. Variação radial e longitudinal da densidade básica da madeira de Pinus elliottii Engelm. com diferentes idades. Ciência da Madeira, v. 4. n. 1, p. 83-92, 2013. DOI: 10.12953/2177-6830. v04n01a07.

Osborne, N. L. Estimating the density of coast Douglas-fir wood samples at diferente moisture contents using medical X-ray computed tomography. Computers and Electronics in Agriculture, v. 127, p. 50-55, 2016. DOI: 10.1016/j.compag.2016.06.0030168-1699.

Peres, M. L. et al. Idade de segregação do lenho juvenil e adulto pela variação da massa específica de açoita-cavalo. Ciência Rural, v. 42, n. 9, p. 1596-1602, 2012. DOI: 10.1590/S0103-84782012000900013.

Rolim, M. B. \& Ferreira, M. Variação da densidade básica da madeira produzida pela Araucaria angustifolia (Bert.) O. Kuntze em função dos anéis de crescimento. Revista IPEF, n. 9, p. 47-55, 1974.

Santini, J. E. et al. Análise comparativa das propriedades físicas e mecânicas da madeira de três coníferas de florestas plantadas. Ciência Florestal, v.10, n.1, p. 85-93, 2000. DOI: 10.5902/19805098397.

Trevisan, R. et al. Axial variation of basic density of Araucaria angustifolia wood in different diameter classes. Ciência Rural, v. 46, n. 11, p. 1969-1972, 2016. DOI: 10.1590/0103-8478cr20141312.

United States. Department of Agriculture. Forest Service. Wood handbook: as an engineering material. Madison,, 1999. 486 p.

Vital, B. R. Métodos de determinação da densidade da madeira. Boletim Técnico-SIF, n. 1, 1984. 21 p. 